\title{
Inexpensive and universal growth media for biomass production of microalgae
}

\author{
Zabochnicka-Świątek M. ${ }^{1,}{ }^{*}$, Kamizela T. ${ }^{1}$, Kowalczyk M. ${ }^{1}$, Kalaji H.M..$^{2,3}$ and Bąba W. ${ }^{4}$ \\ ${ }^{1}$ Czestochowa University of Technology, Institute of Environmental Engineering, Brzeźnicka 60a, 42-200 Czestochowa, Poland \\ ${ }^{2}$ Department of Plant Physiology, Faculty of Agriculture and Biology, Warsaw University of Life Science - SGGW, Nowoursynowska 159, \\ 02-776 Warsaw, Poland \\ 3Institute of Technology and Life Sciences (ITP), Falenty, Al. Hrabska 3, 05-090 Raszyn, Poland \\ ${ }^{4}$ Department of Plant Ecology, Institute of Botany, Jagiellonian University, Lubicz 46, 31-512, Kraków, Poland \\ Received: 20/12/2017, Accepted: 07/02/2019, Available online: 08/02/2019 \\ *to whom all correspondence should be addressed: e-mail: mzabochnicka@is.pcz.czest.pl \\ https://doi.org/10.30955/gnj.002558
}

\section{Abstract}

New challenges for the industrial microbiology and biotechnology of algae are to increase the efficiency of microalgal growth rates and to decrease the cultivation costs. Algae could be cultivated in fresh water as well as in salty sea water or wastewater. Microalgal biomass can be used as a sorbent to remove microcontaminants (e.g. heavy metals, biogens) from wastewater. The results proved that it is possible to use an inexpensive and universal growth medium (Bioflorin) together with a popular fertilizer, like Bristol $(\mathrm{Br})$ or Blue Green medium (BG-11), to cultivate Chlorella vulgaris and Scenedesmus armatus. The mixotrophic condition can be suitable for the cultivation of Chlorella vulgaris and Scenedesmus armatus. The highest concentrations of algal biomass for both species were achieved on the Bioflorin medium, followed by the BG-11 medium and finally on the Bristol medium in autotrophic as well as mixotrophic conditions. The number of $C$. vulgaris cells under mixotrophic conditions was higher than that of $S$. armatus. The use of inexpensive growth media could lower the production costs of algal biomass on a large scale.

Keywords: C. vulgaris, S. armatus, decrease in the cultivation costs, microalgae, photoautotrophic and mixotrophic cultivation, physiological activity.

\section{Introduction}

Microalgal biomass can be used as a sorbent to remove microcontaminants (e.g. heavy metals, biogens) from wastewater as well as a feedstock in different industries, for example to produce biofuels and generate energy, to produce fertilizers, to make cosmetics and pharmaceuticals (Krzywonos et al., 2014; ZabochnickaŚwiątek, 2010, 2013; Zabochnicka-Świątek and Malińska, 2012; Zabochnicka-Świątek et al., 2014). Microalgae can also be used for nutritional purpose (Koller et al., 2014). Current studies on the production of microalgal biomass focus on developing and improving the methods for microalgal cultivation that would allow increasing the efficiency of microalgal growth rates and decreasing the cultivation costs (Becker, 2008; Gouveia and Oliveira, 2009; Nayak et al., 2013).

Algae could be cultivated in fresh water as well as in salty sea water and wastewater. Some researchers have indicated that the most important factor for growing algae is the availability of nutrients [Krzywonos et al., 2014; Krzemińska et al., 2014; Zabochnicka-Świątek, 2017]. The biomass yield during autotrophic cultivation is limited by the growth rate, low light penetration and photoinhibition (Juntila et al., 2015). During the autotrophic growth, microalgae assimilate $\mathrm{CO}_{2}$ from the atmosphere (Gouveia and Oliveira, 2009; Zabochnicka-Świątek, 2012). Heterotrophic cultivation requires a carbon source with no light, whereas mixotrophic cultivation requires less carbon input than heterotrophy and light is only complementary (Juntila et al., 2015; Kim et al., 2013]. However, the high cost of organic carbon is a limiting factor for the heterotrophic cultivation of algae (Zheng et al., 2012).

Regardless of the mode of cultivation, microalgae can be grown in two types of systems, i.e. open (outdoor) and closed systems. Cultivation of microalgae in open systems is performed in artificial (i.e. photobioreactors) or natural aquifers (e.g. ponds) and is cheaper than cultivation in closed systems. The source of light is solar radiation in open systems and artificial light in closed systems (Zabochnicka-Świątek and Krzywonos, 2014). Cultivation of microalgae in closed systems allows one to achieve higher biomass productivity and to control the cultivation conditions more easily.

Numerous studies have demonstrated that heterotrophic cultivation of microalgae helps to obtain higher biomass yields than when they are cultivated under conventional autotrophic conditions (Juntila et al., 2015; Turon et al., 2015). Moreover, some microalgal species can be grown in autotrophic as well as heterotrophic conditions. It was confirmed that $C$. vulgaris can grow 
when the light and $\mathrm{CO}_{2}$ are available or in the dark, providing that thesource of external organic carbon is available (Becker, 2008). For example, Chlorella vulgaris and Scenedesmus sp. are classified as the fastest growing microalgae and are rich in valuable constituents that can be later used for production of biofuels, fertilizers, etc. $C$. vulgaris contains $14-22 \%$ of lipids, $51-58 \%$ proteins, $12-17 \%$ of carbohydrates and $4-5 \%$ of nucleic acids (Kim et al., 2010). These two species of microalgae are very common in nature, and thus easily available. This is the reason why $C$. vulgaris and $S$. armatus were selected for the present study. The selection of an algal multiplication technology influences the cost-efficiency of algal biomass utilized for energy (Dębowski et al., 2013). Currently, there are a number of studies on the potential of various types of microbial biomass that can be used for a wide range of applications, e.g. for recovery of metals from waste materials (Willner et al., 2015). The application of algal biomass for energy purposes would require a high yield of biomass over time at the lowest operating costs. There are still gaps in our knowledge about inexpensive cultivation methods of microalgae, prior to introducing them on an industrial scale.

In order to reduce the production costs, inexpensive and universal media for cultivation and maintenance of algae are needed. Popular fertilizers for algal cultivation are Bristol or BG-11 (Allen and Steiner, 1968; Bold, 1949). Moreover, the mixotrophic growth of microalgae requires continuous delivery of organic carbon sources, which is usually expensive and hence the use of inexpensive organic carbon compounds will additionally reduce the cultivation costs. Therefore, the overall goal of this study was to select the type of cultivation and growth medium that would enable the highest growth rate of $C$. vulgaris and $S$. armatus as well as lower cultivation costs. This study focuses on the mixotrophic cultivation of microalgae at decreased cultivation costs. The innovative aspect is the possibility of applying inexpensive organic carbon sources during the mixotrophic cultivation and an inexpensive growth medium.

The literature provides descriptions of molasses-based growth and lipid production of several algal strains (EISheek et al., 2014; Gaurav et al., 2016; Gautam et al., 2013; Mondal et al., 2016; Mondal et al., 2017). However, there still remains a gap in knowledge on a possible use of an inexpensive and universal growth medium (Bf), together with popular fertilizers: Bristol or BG-11 to increase the physiological activity of the Chlorella vulgaris and Scenedesmus armatus.

The scope of the study included: (i) an analysis of the effects of a cultivation type and growth medium on selected algal species, (ii) an analysis of the growth rate and cell density, (iii) determination of the effect of cultivation on the production of oxygen and chlorophyll a by microalgae, (iv) an analysis of changes in $\mathrm{pH}$ during the cultivation, and (v) an economic analysis.

\section{Materials and methods}

\subsection{Experimental procedure}

Batch-fed cultivation of algae was performed in $500 \mathrm{~cm}^{3}$ glass bottles (in static conditions) sterilized at $160^{\circ} \mathrm{C}$ for 2 $\mathrm{h}$ prior to use. The laboratory experiments were conducted for 20 days in autotrophic and mixotrophic conditions. The addition of an external source of carbon allowed us to conduct the process in mixotrophic conditions, where $5 \mathrm{~cm}^{3}$ solution of molasses $(\mathrm{m})$ of a concentration of $0.15 \mathrm{~g} / \mathrm{L}$ of molasses in the final medium was added to each bottle daily at the beginning of the dark phase. Molasses can be used for enhancing the growth of microalgae in heterotrophic and mixotrophic conditions. Molasses contains 25\% of glucose, $25 \%$ of fructose and $30 \%$ of sucrose (Becker, 2008).

The samples were placed in a phytotron chamber with the temperature set at $29^{\circ} \mathrm{C}$ during the day and at $25^{\circ} \mathrm{C}$ during the night. During the day, the light at an intensity of photosynthetically active radiation (PAR) was set at 80 $\mu \mathrm{mol} / \mathrm{m}^{2} \mathrm{~s}$ in cycles of $12 \mathrm{~h}$ for a bright phase and $12 \mathrm{~h}$ for a dark phase. The algal cultivation was conducted in the batch-fed system. C. vulgaris (Cv) and S. armatus (Sc) were selected for the study. The strains of unicellular green microalgae $C$. vulgaris and $S$. armatus were obtained from the Culture Collection of Baltic Algae (CCBA), Institute of Oceanography, University of Gdansk, Poland. Algal species were sampled during the phase of the exponential growth and the initial concentration was 0-3 g/L of $\mathrm{Cv}$ and 0.4-0.8 $\mathrm{g} / \mathrm{L}$ of Sc and cell density was $2.5 \times 10^{6}$ cells $/ \mathrm{cm}^{3}$.

\subsection{Growth media}

The selected growth media were prepared in a laboratory by adding a commonly available fertilizer for green plants, i.e. Bioflorin (Bf) (Tropical, Poland) for general cultivation, to growth media recommended for algae, i.e. Bristol $(\mathrm{Br})$ and Blue Green medium (BG-11). Table 1 presents the chemical composition of the selected growth media.

Table 1. Composition of growth media

\begin{tabular}{cccc}
\hline \multirow{2}{*}{ Constituents } & Bioflorin & BG-11 & Bristol \\
\cline { 2 - 4 } & \multicolumn{2}{c}{ Final concentration, g/L } \\
\hline $\mathrm{NaNO}_{3}$ & 0.008 & 1.5 & 0.25 \\
\hline $\mathrm{CaCl}_{2} \times 2 \mathrm{H}_{2} \mathrm{O}$ & - & 0.036 & 0.25 \\
\hline $\mathrm{MgSO}_{4} \times 7 \mathrm{H}_{2} \mathrm{O}$ & - & 0.075 & 0.075 \\
\hline $\mathrm{K}_{2} \mathrm{HPO}_{4}$ & - & 0.04 & 0.075 \\
\hline $\mathrm{K}_{2} \mathrm{O}$ & 0.0325 & - & - \\
\hline $\mathrm{P}_{2} \mathrm{O}_{5}$ & 0.015 & - & - \\
\hline \multicolumn{4}{c}{ Trace metals } \\
\hline $\mathrm{Mn}$ & - & 0.00181 & - \\
\hline $\mathrm{Zn}$ & 0.0001 & 0.00022 & - \\
\hline $\mathrm{Mo}$ & 0.0003 & 0.00039 & - \\
\hline $\mathrm{Cu}$ & 0.0005 & 0.00008 & - \\
\hline $\mathrm{Co}$ & 0.00005 & 0.00005 & - \\
\hline $\mathrm{B}$ & 0.0005 & 0.00286 & - \\
\hline $\mathrm{Fe}$ & 0.005 & 0.006 & - \\
\hline
\end{tabular}

The BG-11 and Bioflorin growth media contained more nutrients than the Bristol one. The latter contained only six general nutrients and showed no content of trace metals which are necessary for microalgal growth (i.e. Zn, 
$\mathrm{Cu}$, etc.). Bioflorin is a liquid plant fertilizer with the composition of macro- and microelements required for plant growth. The growth media used in this study differed in the chemical composition. BG-11 contained not only basic nutrients and trace metals but also other compounds (e.g. $\mathrm{Na}_{2} \mathrm{CO}_{3}$, EDTA, citric acid) with buffering properties. Also, BG-11 and Bioflorin contained trace quantities of $\mathrm{Zn}, \mathrm{Mo}, \mathrm{Cu}, \mathrm{Co}$ and $\mathrm{B}$, which additionally facilitated the growth of microalgal biomass. Moreover, BG-11 contained $\mathrm{Mn}$ and Bioflorin contained Fe. Control experiments, which contained only $C$. vulgaris and $S$. armatus with no addition of growth media, were also performed to gain understanding of the influence of growth media on the growth rate of algal biomass.

\subsection{Analytical methods}

The concentration of biomass was determined from the number of cells counted in a Thoma chamber and as dry matter according to PN-C-04541:1978 (PN-C-04541:1978). The size of algal cells was determined under a microscope (NIKON Eclipse E200) integrated with a colour digital camera (DS-Fi1) and software (NIS Basic Research). The $\mathrm{pH}$ was measured with a Cybercan pH11 meter (Eutech Instruments) according to PN-EN ISO 10523:2012 (PN-EN ISO 10523:2012), dissolved oxygen was measured with CO-401 meter (Elmetron) according to PN-EN ISO 5814:2013-04 (PN-EN ISO 5814:2013-04), and the content of chlorophyll $a$ was determined according to PN-ISO 10260:2002P (PN-ISO 10260:2002P). All the measurements were conducted in triplicates and the data are presented as arithmetic means calculated from three measurements.

\section{Results and discussion}

\subsection{Effects of growth media on C. vulgaris and S. armatus growth}

In this study, biomass was determined with two methods: (1) measuring dry matter and (2) counting algal cells in a Thoma chamber. The number and size of algal cells were determined under a microscope. Figure 1 shows the biomass concentrations of the investigated microalgae determined from the measurement of dry matter. The concentration of algal biomass grown on a selected medium in mixotrophic condition was lower in each case than the concentration of algal biomass obtained in autotrophic conditions. An increase in the concentration of biomass from both species grown without any growth medium (the control samples) was insignificant during the entire experiment and the biomass concentration did not exceed $1 \times 10^{3} \mathrm{mg} / \mathrm{L}$. Similar results were obtained using the $\mathrm{Br}$ medium in mixotrophic conditions.

The highest concentrations of algal biomass for both species were determined after the application of the $\mathrm{Bf}$ medium, lower after the BG-11 medium and the lowest after the $\mathrm{Br}$ medium in autotrophic as well as mixotrophic conditions. Some differences in the total biomass were observed between the selected species. Figure 2 presents the number of microalgal cells (cell density) counted in a Thoma chamber.
An analysis of the effects of the selected growth media on the concentration of biomass (Figure 1) and the number of microalgal cells (Figure 2) showed that in both species the application of $\mathrm{Bf}$ was the most beneficial, followed by BG-11. The cultivation method and medium composition have an impact on the number of cells.

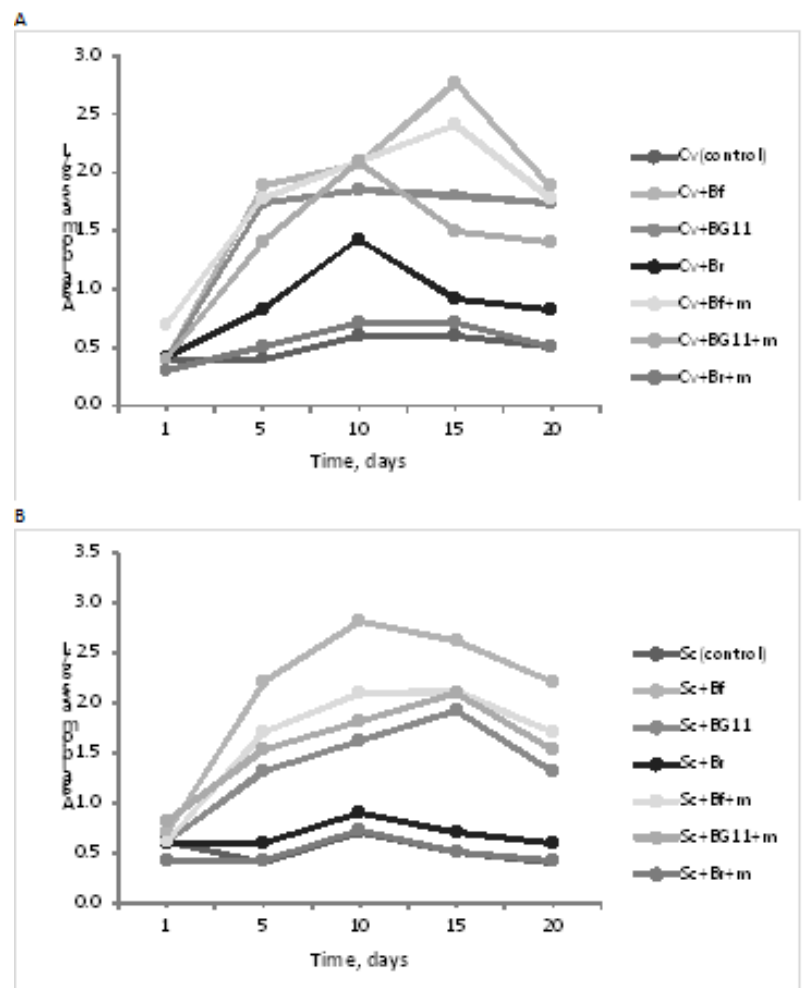

Figure 1. Changes in the concentration of algal biomass of (A) $C$. vulgaris (A) and (B) S. armatus

During the growth of the microalgal populations in a batch-fed system, the following phases can be distinguished: adaptive (i.e. lag, induction), exponential (i.e. logarithmic), declining growth, stationary and death (Miksch and Sikora, 2010). Both microalgal species grown with the addition of the selected media and without any media (the control) entered the declining growth and stationary phases from day 6 . In the control, the algal culture entered the death phase from day 12-13. The growth media caused diverse effects on the occurrence of the microalgal growth phases. The number of algal cells in the control was significantly lower than after the application of any of the selected growth media. Until day 10 in the case of $C$. vulgaris and until day 12 in the case of S. armatus, the population growth was similar for the algal culture grown with and without the addition of the selected media. After the application of BG-11, the first phase of logarithmic growth, which lasted from day 1 to day 5, was followed by the declining growth and stationary phases (from day 5 to day 10). Then, another phase of logarithmic growth (from day 10 to day 13) occurred and was followed by the declining growth phase. It has to be pointed out that some differences between the species were observed. The maximum number of algal cells, i.e. $21 \times 10^{6}$ cells $/ \mathrm{cm}^{3}$, was observed for $C$. vulgaris on day 20 after the addition of BG-11 in the autotrophic and 
mixotrophic conditions. This growth medium contributed to the highest increase in the population of $S$. armatus, so that on day 20 the number of algal cells was about $16 \times 10^{6}$ cells $/ \mathrm{cm}^{3}$.

Slightly lower values of algal cell numbers were observed after the application of $\mathrm{Bf}$, and then following $\mathrm{Br}$. However, an increase in the microalgal population of $S$. armatus was similar for both BG-11 and Bf media during the entire experiment. Based on the results presented in Figures 1 and 2, the least beneficial effect on the biomass growth was observed for $\mathrm{Br}$. All the time. the concentration of microalgal biomass for $C$. vulgaris was higher than the concentration of microalgal biomass for $S$. armatus. The total number of cells was consistently higher for $C$. vulgaris than for S. armatus.

As shown in Table 2, the maximum growth rate and algal cell density were observed on different days. C. vulgaris and $S$. armatus showed the maximum growth rate before the maximum cell density was reached. C. vulgaris reached the highest growth rate and cell density of 0.59 $\mathrm{mg} / \mathrm{L}$ day $^{-1}$ and $\sim 21 \times 10^{6}$ cells $/ \mathrm{cm}^{3}$, respectively. Compared with the mixotrophic growth, the autotrophic culture of $C$. vulgaris showed higher growth after the application of $\mathrm{Bf}$ and $\mathrm{Br}$. The growth rate of $S$. armatus was higher in all autotrophic cultures compared to mixotrophic conditions. S. armatus reached the highest growth rate and cell density of $0.84 \mathrm{mg} / \mathrm{L}$ day ${ }^{-1}$ and $16 \mathrm{x}$
$10^{6}$ cells $/ \mathrm{cm}^{3}$, respectively. S. armatus showed the higher growth after the application of Bf and then after BG-11

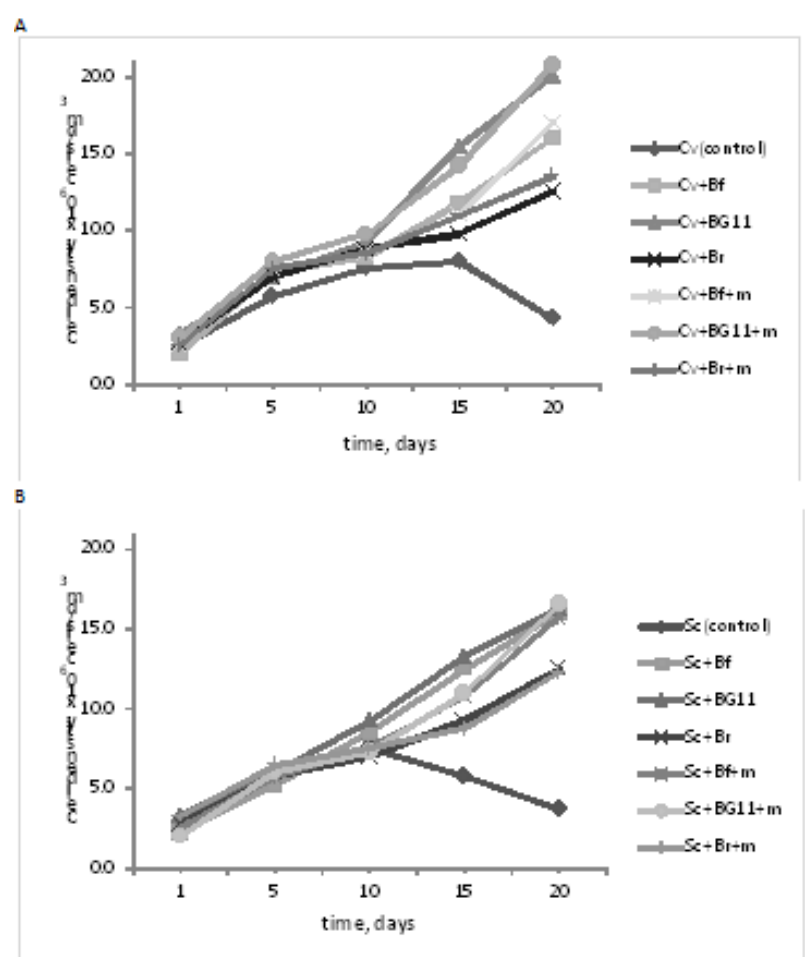

Figure 2. Increase in the population of microalgae from the selected species (A) C. vulgaris and (B) S. armatus

Table 2. Autotrophic and mixotrophic culture of $C$. vulgaris and S. armatus under different conditions. Data are represented as the average \pm standard deviation of three independent replicate cultures

\begin{tabular}{|c|c|c|c|c|c|}
\hline Cultivation & Sample & $\begin{array}{l}\text { Growth rate } \\
\text { (mg/L day-1) }\end{array}$ & $\begin{array}{l}\text { Culture time } \\
\text { (day) }\end{array}$ & $\begin{array}{l}\text { Cell density }\left(\times 10^{6}\right. \\
\text { cells/cm3) }\end{array}$ & Culture time (day) \\
\hline \multicolumn{6}{|c|}{ C. vulgaris } \\
\hline \multirow{4}{*}{ Autotrophic } & $\mathrm{Cv}$ (control) & 0.10 & 11 & 8 & 15 \\
\hline & $\mathrm{Cv}+\mathrm{Bf}$ & 0.54 & 17 & 16 & 20 \\
\hline & $\mathrm{Cv}+\mathrm{BG} 11$ & 0.52 & 10 & 20 & 20 \\
\hline & $\mathrm{Cv}+\mathrm{Br}$ & 0.37 & 10 & 13 & 20 \\
\hline \multirow{3}{*}{ Mixotrophic } & $\mathrm{Cv}+\mathrm{Bf}+\mathrm{m}$ & 0.41 & 17 & 17 & 20 \\
\hline & $\mathrm{Cv}+\mathrm{BG} 11+\mathrm{m}$ & 0.59 & 10 & 21 & 20 \\
\hline & $\mathrm{C} v+\mathrm{Br}+\mathrm{m}$ & 0.14 & 10 & 13 & 20 \\
\hline \multicolumn{6}{|c|}{ S. armatus } \\
\hline \multirow{4}{*}{ Autotrophic } & Sc (control) & 0.13 & 10 & 6 & 15 \\
\hline & $\mathrm{Sc}+\mathrm{Bf}$ & 0.84 & 10 & 16 & 20 \\
\hline & $\mathrm{Sc}+\mathrm{BG} 11$ & 0.42 & 13 & 16 & 20 \\
\hline & $\mathrm{Sc}+\mathrm{Br}$ & 0.39 & 17 & 12 & 20 \\
\hline \multirow{3}{*}{ Mixotrophic } & $\mathrm{Sc}+\mathrm{Bf}+\mathrm{m}$ & 0.46 & 13 & 16 & 20 \\
\hline & $\mathrm{Sc}+\mathrm{BG} 11+\mathrm{m}$ & 0.14 & 10 & 16 & 20 \\
\hline & $\mathrm{Sc}+\mathrm{Br}+\mathrm{m}$ & 0.10 & 17 & 12 & 20 \\
\hline
\end{tabular}

The microscopic analysis performed on day 20 of the experiment (not presented here) provided evidence for an evaluation of the number and size of algal cells, and thus allowed us to link the counts of algal cels with the measured concentrations of biomass and the number of cells counted in a Thoma chamber. The algal cultures without growth media showed a low number of algal cells for both algal species. Generally, algal cells exposed to the growth media yieldedmore numerous populations of both algal species. In addition, the number of algal cells for was higher for all the growth media applied than that $\mathrm{S}$. armatus. This is confirmed by the data presented in Figures 1 and 2 .

The cells of $C$. vulgaris grown in the mixotrophic conditions were bigger than these grown in autotrophic conditions. This phenomenon was not observed for the cells of $S$. armatus.

The results indicate that by growing microalgae of Chlorella vulgaris and Scenedesmus armatus species with 
the addition of various growth media and under different cultivation conditions (autotrophic and mixotrophic) it was possible to evaluate the effects of the composition of a growth medium and a cultivation type on the biomass growth rate.

Microalgae are often grown in phototrophic and heterotrophic conditions. However, it has to be pointed out that microalgae grow better in photoheterotrofic/mixotrophic conditions (Yeh et al., 2012). The current results have confirmed the findings reported in the literature. An increase in the cell counts of C. vulgaris and S. armatus was observed in all the growth media and under both cultivation conditions (authotrophic and mixotrophic conditions). The results prove that microalgae of $C$. vulgaris and $S$. armatus can use an external source of organic carbon, which contributed to an increase in the biomass growth.

\subsection{Effects of growth media on C. vulgaris and S. armatus photosynthetic activity}

The type of cultivation had an effect on the production of oxygen and chlorophyll a by the selected algae species. Like $\mathrm{pH}$, the production of oxygen released into the environment is an indicator of the efficiency of photosynthesis (Figure 3). During the cultivation of microalgae in autotrophic conditions, irrespective of the selected growth media, the curves presenting changes in the concentrations of dissolved oxygen showed a similar trend. In comparison to autotrophic conditions, mixotrophic conditions had an effect on changes in the physiological activity of the microalgal populations, which is illustrated by all the curves plotted for both species. In the case of $C$. vulgaris grown with the addition of BG-11 or $\mathrm{Br}$, mixotrophic conditions resulted in two peaks of dissolved oxygen: the first occurred on day 10 and the second on took place on day 20. In the cultivation of both species with the addition of $\mathrm{Bf}$ in mixotrophic conditions, the peak of dissolved oxygen was observed on day 10 of the experiment. These tendencies reflected changes in the $\mathrm{pH}$ of the investigated samples taking place at approximately the same time. A gradual decrease in dissolved oxygen was observed from day 5 in all samples with the supplemented growth media in autotrophic conditions, whereas in the samples without the growth media (grown in water) such a gradual decrease occurred on day 1 . Higher concentrations of oxygen in the cultures grown on the BG-11 (14-15 $\left.\mathrm{mgO}_{2} / \mathrm{L}\right)$ and $\mathrm{Br}\left(11 \mathrm{mgO}_{2} / \mathrm{L}\right)$ media in mixotrophic conditions observed on the last day of the experiment indicated that the addition of of an external source of carbon enhanced the physiological activity of the investigated microalgal populations. This shows that an algal culture in mixotrophic conditions the can be kept in the growing phase for longer time than cultures grown in autotrophic conditions. The increase in the oxygen concentration resulted from the photosynthetic processes and proceeded in the algal cultures that were supplied with all nutrients, thus contributing to the increased population growth of the investigated microalgae.
The lowest concentration of dissolved oxygen was observed after adding the $\mathrm{Bf}$ medium in mixotrophic conditions. The concentration of dissolved oxygen was $<2$ $\mathrm{mgO}_{2} / \mathrm{L}$ from day 15 for $C$. vulgaris and from day 18 for $S$. armatus. These values were lower than in the control sample.

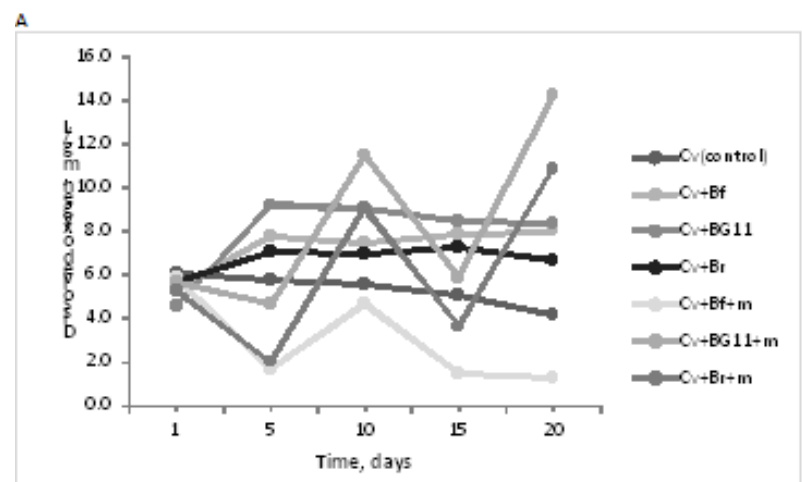

B

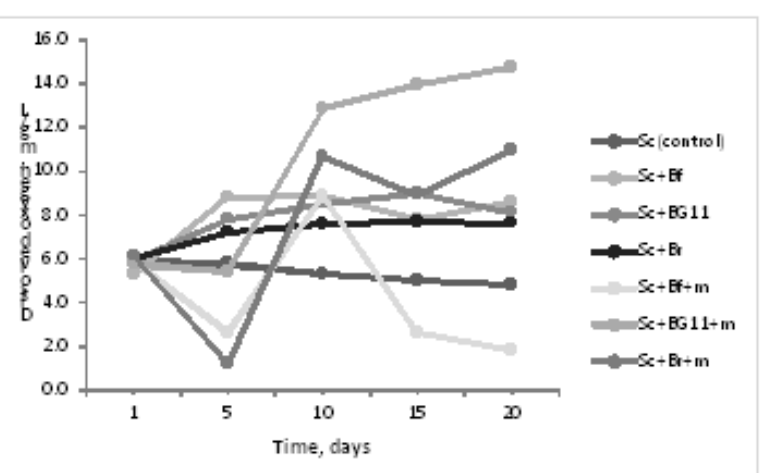

Figure 3. Changes in the concentrations of dissolved oxygen (DO) observed during the cultivation of (A) C. vulgaris and (B) S. armatus

The mixotrophic cultivation had an effect on some changes in the physiological activity of microalgae. The higher concentrations of oxygen reported on the last day of the experiment in the mixotrophic cultures with the BG-11 and $\mathrm{Br}$ media proved that the addition of an external source of organic carbon had a beneficial effect on the physiological activity of the investigated algal species. However, the lowest concentration of dissolved oxygen was determined after the addition of $\mathrm{Bf}$ in mixotrophic conditions. Irrespective of the growth media, autotrophic cultivation showed a similar tendency of changes in concentrations of dissolved oxygen.

Figure 4 presents changes in the content of chlorophyll a observed during the experiment. Mixotrophic cultivation stimulated an increase in the concentrations of chlorophyll a. The highest concentration of chlorophyll a was reported for both species with the addtion of the BG-11 and Bf growth media. The highest content of chlorophyll a was observed in the culture of Chlorella vulgaris with the addition of the BG-11 in mixotrophic conditions $(5.2 \mathrm{mg} / \mathrm{L})$ and $\mathrm{Bf}$ in mixotrophic conditions $(4.2 \mathrm{mg} / \mathrm{L})$. A similar tendency was observed for the cultures of Scenedesmus armatus. The highest content of chlorophyll 
a was observed for the cultures with the addition of the $\mathrm{Bf}(4.4 \mathrm{mg} / \mathrm{L})$ and $\mathrm{BG}-11(4.1 \mathrm{mg} / \mathrm{L})$ media in mixotrophic conditions.
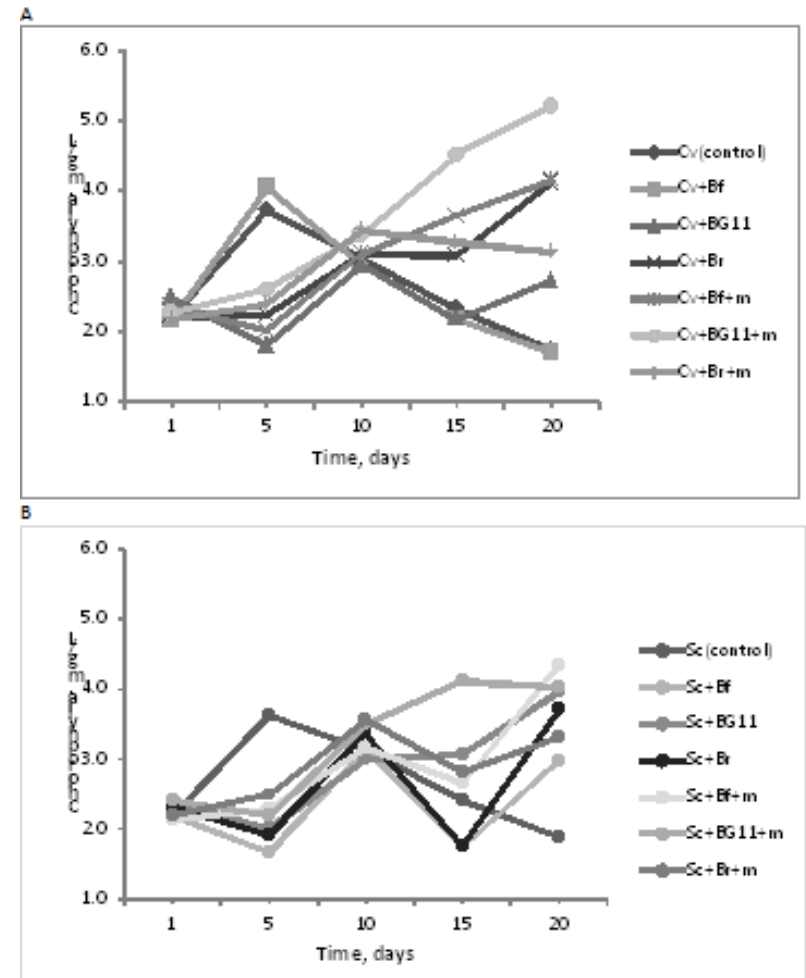

Figure 4. Changes in the content of chlorophyll $a$ observed during the cultivation of (A) C. vulgaris and (B) S. armatus

The number of cells differed between the investigated species. Generally, the concentrations of biomass (determined from dry matter) obtained from growing $C$. vulgaris were higher than the ones achieved by $S$. armatus. As for the selected growth media, the concentrations of biomass were lower in mixotrophic than in autotrophic conditions. The application of the Bf medium was the most beneficial for both species, with the BG-11 being the second best in this respect. The addition of the $\mathrm{Br}$ medium showed the least beneficial effect under both autotrophic and mixotrophic conditions.

The dynamics of cell growth and division are governed by typical cell metabolism and physiological processes such as photosynthesis, respiration, ion assimilation, etc. (Kozieł and Włodarczyk, 2011). The reported changes in $\mathrm{pH}$, concentrations of oxygen and chlorophyll a corresponded to the phases of microalgal growth. The supply of an additional source of carbon had an effect on the production of chlorophyll a. Regarding the cultivation in autotrophic conditions, the curves of changes in dissolved oxygen and $\mathrm{pH}$ showed similar trends, irrespective of the applied growth media.

\section{3. $\mathrm{pH}$ variation}

One of the indicators of biomass growth is $\mathrm{CO}_{2}$ assimilation during photosynthesis. The assimilation of $\mathrm{CO}_{2}$ is indirectly affected by $\mathrm{pH}$. The higher the $\mathrm{pH}$, the more efficient the $\mathrm{CO}_{2}$ assimilation. This results in decreasing acidity of an algal culture. Figure 5 presents the $\mathrm{pH}$ variations that were observed during the cultivation of microalgae grown on the selected growth media.

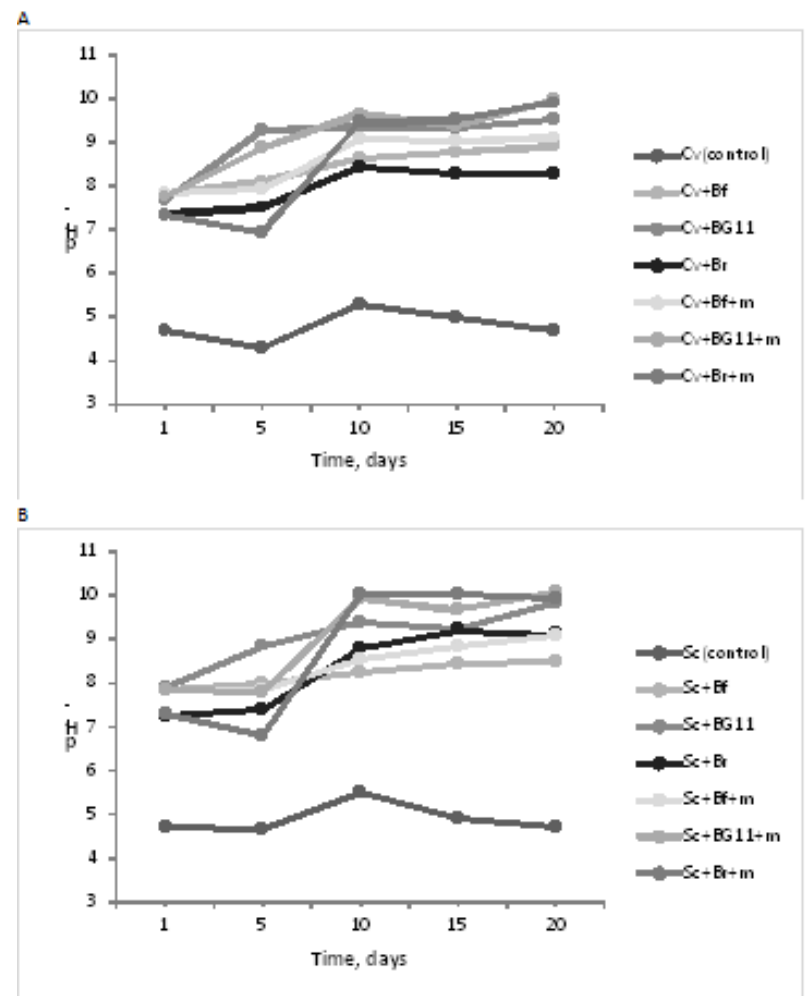

Figure 5. Changes in $\mathrm{pH}$ observed during the cultivation of $(\mathrm{A}) \mathrm{C}$. vulgaris and (B) S. armatus

In the samples with the growth media, the $\mathrm{pH}$ values were much higher than in the control sample (without any growth medium). The addition of growth media was beneficial as no significant fluctuations in $\mathrm{pH}$ were observed. In contrast, fluctuations in $\mathrm{pH}$ were observed in the control samples. This indicates that $\mathrm{CO}_{2}$ assimilation in the process of photosynthesis was low in the control samples because of the lack of micro- and macronutrients in the cultivating solution.

From day 10 of the experiment, changes in $\mathrm{pH}$ were not as significant as during the first few days. After 10 days, the $\mathrm{pH}$ values in all samples with Scenedesmus armatus ranged from 8.3 to 10.4, whereas the $\mathrm{pH}$ in the samples with Chlorella vulgaris varied from 7.9 to 10.2. The lowest values of $\mathrm{pH}$ were observed in the control ( $\mathrm{C} v$ and $\mathrm{Sc}$ ). During the growth of both populations, the observed $\mathrm{pH}$ increase in time indicated that $\mathrm{CO}_{2}$ assimilation and photosynthesis processes occurred continuously. During the autotrophic growth, the increased consumption of $\mathrm{CO}_{2}$ in the photosynthetic process resulted from the growth of microalgal biomass, leading to the formation of $\mathrm{OH}^{-}$ions and consequently a higher $\mathrm{pH}$ of the solution (Becker, 2008; Kim et al., 2013). Initially, the values of pH could be affected by the type of a growth medium because on day 1 the $\mathrm{pH}$ was lower in the culture with the $\mathrm{Br}$ medium (7.3) than in the samples with the other media. Then, $\mathrm{pH}$ 
increased in all samples due to the photosynthetic processes. Similar results were obtained by Nayak et al. (2013), who observed arelationship between $\mathrm{pH}$ and time assigned to growing microalgae of Scenedesmus sp. species (Nayak et al., 2013). These researchers grew microalgae in a photobioreactor at continuous light regime for 12 days and observed that $\mathrm{pH}$ of the microalgal culture increased from 6.5 to 7.5 with time. Tam and Wong (1996) reported lower pH during the logarithmic phase and higher $\mathrm{pH}$ during the lag and stationary phases. These findings support the results obtained in the present study. It has to be pointed out that excessively high values of $\mathrm{pH}$ can impair the mechanisms in algal cells on the biochemical level, causing some disturbances in the metabolism of sugars in C. vulgaris (Mayo, 1997).

The lowest $\mathrm{pH}$ values of 6.92 ( $\mathrm{Cv}$ - control sample) and 6.78 (Sc - control sample) were observed under mixotrophic conditions. During the mixotrophic growth, inorganic and organic carbons are metabolized and hydroxyl ions and $\mathrm{CO}_{2}$ are generated as metabolites, while the $\mathrm{pH}$ variation is irregular (Kim et al., 2013).

\subsection{Economic analysis}

According to the literature, the production cost of algal biomass produced in the PBR (tubular) system is 9-10€/1 kg (Slade and Bauen, 2013). The Bioflorin growth medium is very cheap $-(8 € / L)$ and this commonly available fertilizer for green plants, as mentioned above, contains more nutrients than Bristol. The Bristol medium is much more expensive: $\sim 50 € / L$ and the price for the BG-11 medium is $\sim 312 € / L$. Molasses is also a inexpensive source of carbon ( $8 € / 1 \mathrm{~kg}$ ) for mixotrophic cultivation of algae, and then the cost of biomass production is $\sim 3-4 € / 1 \mathrm{~kg}$.

\section{Conclusions}

The results confirmed that it is possible to use an inexpensive and universal growth medium (Bf) and a carbon source (molasses) in place of the popular fertilizers: Bristol or BG-11, to cultivate Chlorella vulgaris and Scenedesmus armatus. The use of inexpensive rowth media will reduce the production costs of algal biomass on a large scale.

The results from the present study justify the following conclusions: the highest concentrations of algal biomass for both species were obtained after the application of the Bf medium, lower after the BG-11 medium and the lowest after the $\mathrm{Br}$ medium in autotrophic as well as mixotrophic conditions. Hence, further research will focus on the selection of an efficient method for the production of microalgal biomass depending on time constraints, calorific value of biomass and the investment costs. Microalgal biomass can be used as a sorbent for removal of microcontaminants (heavy metals and/or biogens) from wastewater.

\section{Acknowledgment}

This research was supported by the grant BS/PB-401-301/11.

\section{References}

Allen M.M. and Steiner R.Y. (1968), Selective isolation of bluegreen algae from water and soil, Journal of General Microbiology, 51, 203-209.

Becker E.W. (2008), Microalgae: Biotechnology and Microbiology, Cambridge Studies in Biotechnology, 10, Cambridge University Press, Cambridge.

Bold H.C. (1949), The morphology of Chlamydomonas chlamydogama sp. nov., Bulletin of the Torrey Botanical Club, 76, 101-108.

Dębowski M., Zieliński M., Krzemieniewski M., Dudek M. and Grala A. (2013), Potential of algal biomass cultivation on leachate from dewatered sludge after fermentation, Annual Set The Environment Protection, 15, 1612-1622. (In Polish).

El-Sheek M.M., Bedaiwy M.Y., Osman M.E. and Ismail M.M. (2014), Influence of molasses on growth, biochemical composition and ethanol production of the green algae Chlorella vulgaris and Scenedesmus obliquus, Journal of Agricultural Engineering, 2(2), 20-28.

Gaurav K., Srivastava R., Sharma J. and Singh V. (2016), Molasses-based growth and lipid production by Chlorella pyrenoidosa: A potential feedstock for biodiesel, International Journal of Green Energy, 13(3), 320-327.

Gautam K., Pareek A. and Sharma D.K. (2013), Biochemical composition of green alga Chlorella minutissima in mixotrophic cultures under the effect of different carbon sources, Journal of Bioscience and Bioengineering, 116(5), 624-627.

Gouveia L. and Oliveira A.C. (2009), Microalgae as a raw material for biofuels production, Journal of Industrial Microbiology \& Biotechnology, 36, 269-274. DOI 10.1007/s10295-008-04956

Juntila D.J., Bautista M.A. and Monotilla W. (2015), Biomass and lipid production of a local isolate Chlorella sorokiniana under mixotrophic growth conditions, Bioresource Technology, 191, 395-398.

Kim J., Lingaraju B.P., Rheaume R., Lee J-Y. and Siddiqui K.F. (2010), Removal of ammonia from wastewater effluent by Chlorella vulgaris, Tsinghua Science and Technology, 15, 391396.

Kim S., Park J., Cho Y-B. and Hwang S-J. (2013), Growth rate, organic carbon and nutrient removal rates of Chlorella sorokiniana in autotrophic, heterotrophic and mixotrophic conditions, Bioresource Technology, 144, 8-13.

Koller M., Muhr A. and Braunegg G. (2014). Microalgae as versatile cellular factories for valued products, Algal Research, 6, 52-63.

Kozieł W. and Włodarczyk T. (2011), Algae - biomass production, Acta Agrophysica, 17(1), 105-116. (In Polish).

Krzemińska I., Pawlik-Skowrońska B., Trzcińska M. and Tys J. (2014), Influence of photoperiods on the growth rate and biomass productivity of green microalgae, Bioprocess and Biosystems Engineering, 37, 735-741.

Krzywonos M., Borowski P., Kupczyk A. and Zabochnicka-Świątek M. (2014), Abatement of $\mathrm{CO}_{2}$ emissions by using motor biofuels, Przemyst Chemiczny, 93(7), 1124-1127.

Mayo A.W. (1997), Effects of temperature and pH on the kinetic growth of unialga Chlorella vulgaris cultures containing bacteria, Water Environment Research, 69(1), 64-72.

Miksch K. and Sikora J. (2010), Biotechnology of Wastewater. Polish Scientific Publishers PWN, Warsaw. (In Polish). 
Mondal M., Ghosh A., Sharma A.S., Tiwari O.N., Gayen K., Das P., Mandal K. and Halder G.N. (2016), Mixotrophic cultivation of Chlorella sp. BTA 9031 and Chlamydomonas sp. BTA 9032 isolated from coal field using various carbon sources for biodiesel production, Energy Conversion and Management, 124, 297-304.

Mondal M., Ghosh A., Tiwari O.N., Gayen K., Das P., Mandal K. and Halder G. (2017), Influence of carbon sources and light intensity on biomass and lipid production of Chlorella sorokiniana BTA 9031 isolated from coalfield under various nutritional modes, Energy Conversion and Management, 145, 247-254.

Nayak M., Rath S.S., Thirunavoukkarasu M., Panda P.K., Mishra B.K. and Mohanty R.C. (2013), Maximizing biomass productivity and $\mathrm{CO}_{2}$ biofixation of microalgae Scenedesmus sp. by using sodium hydroxide, Journal of Microbiology and Biotechnology, 23(9), 1260-1268.

PN-C-04541:1978, Water and wastewater - Determination of dry solids, loss in mass and dissolved solids, dissolved mineral solids and dissolved volatile solids. (In Polish).

PN-EN ISO 10523:2012, Water quality - Determination of pH. (In Polish).

PN-EN ISO 5814:2013-04, Water quality - Determination of dissolved oxygen - Optical sensor method. (In Polish).

PN-ISO 10260:2002P, Water quality - Measurement of biochemical parameters - Spectrometric determination of the chlorophyll-a concentration. (In Polish).

Slade R. and Bauen A. (2013), Micro-algae cultivation for biofules: Cost, energy balance, environmental impacts and future prospects, Biomass and Bioenergy, 53, 29-38.

Tam N.F.Y. and Wong Y.S. (1996), Effect of ammonia concentrations on growth of Chlorella vulgaris and nitrogen removal from media, Bioresource Technology, 57, 45-50.

Turon V., Trably E., Fouilland E. and Steyer J.P. (2015), Growth of Chlorella sorokiniana on a mixture of volatile fatty acids: The effects of light and temperature, Bioresource Technology, 198, 852-860.

Willner J., Kadukova J. and Fornalczyk A. (2015), Biohydrometallurgical methods for metals recovery from waste materials, Metalurgija, 54(1), 255-258.

Yeh K.L., Chen C.Y. and Chang J.S. (2012), pH-stat photoheterotrophic cultivation of indigenous Chlorella vulgaris ESP-31 for biomass and lipid production using acetic acid as the carbon source, Biochemical Engineering Journal, 64, 1-7.

Zabochnicka-Świątek M. (2010), Algae - feedstock of the future, Archivum Combustionis, 30(3), 225-236.

Zabochnicka-Świątek M. (2012), Effect of air and $\mathrm{CO}_{2}$ supply on growth of microalgae Chlorella vulgaris, Proceedings of The 37th International Technical Conference on Clean Coal and Fuel Systems, 03-07.06.2012, Clearwater, Florida, USA, 183-189.

Zabochnicka-Świątek M. (2013), Utilization of Chlorella vulgaris and sediments after $\mathrm{N}-\mathrm{NH}_{4}$ removal containing clinoptilolite for sorption of heavy metals from wastewater, Annual Set, The Environment Protection, 15(1), 324-347.

Zabochnicka-Świątek M. (2017), Removal of Ammonium Nitrogen from Wastewater in the Processes of Sorption and Biosorption, monograph No 324, Czestochowa University of Technology Publishing House, Częstochowa. (In Polish).
Zabochnicka-Świątek M. and Krzywonos M. (2014), Potentials of biosorption and bioaccumulation processes for heavy metal removal, Polish Journal of Environmenta Studies, 23(2), 551561.

Zabochnicka-Świątek M. and Malińska K. (2012), Removal of nitrogen and phosphorous compounds by zeolites and algae, In: Pawłowski A., Dudzińska M.R., Pawłowski L. (Eds.), Environmental Engineering IV, CRC Press, Taylor and Francis Group.

Zabochnicka-Świątek M., Malińska K. and Krzywonos M. (2014), Removal of biogens from synthetic wastewater by microalgae, Environment Protection Engineering, 40(2), 87104.

Zheng Y., Chi Z. and Chen S. (2012), Two-stage heterotrophic and phototrophic culture strategy for algal biomass and lipid production, Bioresource Technology, 103, 484-488. 